\title{
Identification and diversity of multiresistant Corynebacterium striatum clinical isolates by MALDI-TOF mass spectrometry and by a multigene sequencing approach
}

Margarita Gomila", Feliu Renom², Maria del Carmen Gallegos ${ }^{3}$, Margarita Garau ${ }^{3}$, Dolores Guerrero ${ }^{4}$, Joan B Soriano ${ }^{4}$ and Jorge Lalucat ${ }^{5}$

\begin{abstract}
Background: The genus Corynebacterium is composed of Gram-positive bacteria that are widely distributed throughout the environment; these bacteria are also part of the normal microbiota of human skin and mucous membranes. Multiple studies have shown that species of this genus, including C. striatum, become pathogenic to humans under special conditions. Our aim was to determine the characteristics of clinical multiresistant strains of $C$. striatum that were isolated in our geographical region, to determine their diversity, and to compare them with the type strain and with related species. We studied fifty-two strains of $C$. striatum isolated from different hospitals from Mallorca, Spain, mainly from the Hospital Joan March in Bunyola, Mallorca. Most of the strains were isolated from sputum cultures of respiratory samples from patients with chronic obstructive pulmonary disease. To gain further insight into the genetic diversity of the strains, we analysed several housekeeping genes and other genes associated with antibiotic resistance. Strains were also characterised phenotypically by their antibiotic resistance profiles and by MALDI-TOF mass spectrometry analysis.
\end{abstract}

Results: The ITS1 region, gyrA and $r p o B$ were chosen as the appropriate genes in the C. striatum genome to study the genetic diversity of $C$. striatum species and to discriminate between strains. After analysing these three genes, four sequence types (ST2, ST4, ST1 and ST11) were found to be the most abundant. Splits tree analysis of the strains demonstrated that these clinical isolates did not share any alleles with the type strain of the species. Recombination was detected within all of the C. striatum isolates, and different clonal populations were detected within the samples.

Conclusions: Our results demonstrate that the isolates were best identified using gene-based molecular methods; using these methods, the isolated strains were determined to be different from the type strain of C. striatum. The ITS1 region and the gyrA and rpoB genes were selected because of their variability and were the most useful tools for discriminating between strains. The phenotype and antibiotype characteristics of the strains did not seem suitable for typing purposes. MALDI-TOF mass spectrometry can be a useful method for identifying and discriminating between C. striatum strains.

\footnotetext{
* Correspondence: marga.gomila@uib.es

'Unidad de Investigación-Microbiología, Fundación Hospital Son Llàtzer, Ctra.

Manacor, km. 4, 07198 Palma de Mallorca, Illes Balears, Spain

Full list of author information is available at the end of the article
} 


\section{Background}

The genus Corynebacterium includes pathogens, nonpathogenic environmental bacteria, and saprophytic species. The most widely known pathogenic species is $C$. diphtheriae. C. diphtheriae, endemic in many countries, represents a global health problem because of the outbreaks it has caused in recent decades, as documented by the WHO. Characterisation of the strains is needed to obtain a better understanding and microbiological and epidemiological control [1]. In addition to $C$. diphtheriae, other potentially pathogenic species of the genus are C. amycolatum, C. jeikeium, C. macginleyi and C. urealyticum [2-4]. C. xerosis has also been described as an unusual pathogen [5]. Outbreaks of nosocomial infections have been reported for C. pseudodiphtheriticum [6-8] and, remarkably, C. striatum [9-12].

C. striatum is widely disseminated in the environment and constitutes part of the normal microbiota of the skin and mucous membranes. However, it is potentially pathogenic in specific circumstances, including in infections of patients with lasting chronic diseases, frequent and prolonged hospitalisations, exposure to antibiotics against Gram-negative bacteria (which facilitates the selection of Gram positives), the use of invasive procedures and the presence of organic obstructive pathologies [11,12]. Any circumstance wherein there is increased longevity of disease or chronic disease increases the risk of infection and results in infections occurring more frequently.

Although the significance and prevalence of C. striatum as a causative agent of disease are not well understood, this organism has been responsible for a variety of different infections $[11,13]$. Most C. striatum infections reported to date have been found in respiratory samples, with the vast majority of the strains being multiresistant to antibiotics. Leonard et al. and Bradenburg et al. studied the presence of C. striatum in intensive care units, postulating the existence of person-to-person transmission [9,10]. Otsuka et al. [11] described the frequent isolation of C. striatum in long-stay advanced diseases that were subjected to repeated antibiotic courses. In 2007, Renom et al. [12] described the first nosocomial outbreak of this bacterium in patients with chronic obstructive pulmonary diseases (COPD). All of the strains identified in this outbreak were antibiotic multiresistant.

To understand the source of an outbreak, it is very important to have reliable identification and typing methods for the responsible bacteria. Several studies have tried to accomplish this objective $[10,11]$, but none of them employ a methodology for the identification and typing of bacterial strains. The main aim of our study is to determine the parameters for characterisation of clinical multiresistant strains of C. striatum from sputum cultures isolated from the respiratory samples of COPD patients in our geographical region; we aim to determine the diversity of the strains and to compare the isolates with the C. striatum type strain and with related species.

All strains were characterised phenotypically by RapID $\mathrm{CB}^{\circledR}$ Plus strips (Remel Laboratories, Lenexa, KS), by their antibiotic susceptibility profile and also by genomic profiling (ERIC-PCR, Enterobacterial Repetitive Intergenic Consensus-PCR). These experimental methods provided limited resolution. To gain further insight into the diversity of the C. striatum strains, a multilocus sequence typing (MLST) scheme was developed to identify significant intraspecies genetic diversity. MLST, proposed in 1998 by Maiden et al. [14], has shown that nucleotide variation within several core metabolic genes provides portable, reproducible and high-resolution data appropriate for evolutionary and epidemiological investigations. The strains were also analysed using matrixassisted laser desorption ionisation time-of-flight (MALDI-TOF) mass spectrometry. MALDI-TOF has been reported by several studies as a powerful tool with accurate and reproducible results for rapid identification of clinical isolates in the microbiology laboratory. This method is simple, rapid, easy to perform, inexpensive and may ultimately replace routine phenotypic assays $[15,16]$.

\section{Methods}

\section{C. striatum culture collection}

A total of 52 strains of C. striatum (collected between May 2006 and June 2009) were studied from three hospitals located in Mallorca, Spain. All of these strains were analysed and compared with the type strain of C. striatum ATCC $6940^{\mathrm{T}}$ and the type strain of C. amycolatum CCUG $35685^{\mathrm{T}}$, the closest-related species; the isolated strains were also compared with two strains from the culture collection of the Göteborg University (CCUG) that were characterised in a first approach as C. striatum strains (one from a clinical origin and the other environmental). All Corynebacterium strains were isolated and cultured on Columbia agar with 5\% sheep blood (bioMérieux). Prior to cultivation, all samples were Gram-stained to determine the samples that could be discarded; strains that were not representative of the lower respiratory tract and the ones contaminated with microbiota from the upper respiratory tract, according to the Murray and Washington criteria, were not used [17]. The cultivation and incubation of the plates were performed under routine laboratory conditions. All of the strains are shown as Additional file 1: Table S1. 


\section{Phenotypical and antibiotic susceptibility characterisations}

The 56 strains were analysed phenotypically by RapID CB Plus ${ }^{\circledR}$ strips, and their antibiogram profiles were established by E-test assay (AB Biodisk, Solna, Sweden) on Mueller-Hinton agar plates supplemented with $5 \%$ of blood (bioMérieux, Marcy d'Etoile, France), according to CLSI recommendations [18].

\section{DNA extraction: PCR amplification and DNA sequencing} Bacterial genomic DNA for PCR amplifications was obtained as previously described [19]. All C. striatum strains were compared by the ERIC-PCR technique, using the primers ERIC1R (5'-ATGTAAGCTCCTGGGGATTCAC-3') and ERIC2 (5'-AAGTAAGTGACTGGGGTGAGCG-3') [20]. The housekeeping genes, 16S rDNA, ITS1 (internal transcribed spacer 1), gyrB, hsp65, rрoB and $\operatorname{sod} A$, were amplified and sequenced for the 56 strains. Two genes codifying for antibiotic resistance, aph $A$ and $\operatorname{erm} X$, were also amplified and sequenced for these strains. Three other primer sets codifying for antibiotic resistances $(\operatorname{cmx} x, \operatorname{rep} B$ and tet $A$ ) were also tested but did not produce an amplicon. The list of primers is indicated as Additional file 2: Table S2 [21-25]. PCR amplification and sequence reaction was performed as previously described [19].

\section{Allele diversity, nucleotide diversity and statistical analysis}

Allele and nucleotide diversities were calculated from the gene sequences with the DnaSP package, version 3.51 [26]. For identification purposes, distinct allele sequences were assigned arbitrary allele numbers for each locus. For each isolate, the combination of alleles obtained at each locus defined its allelic profile. Each allelic profile constitutes a sequence type (ST), and isolates with identical profiles belonged to the same ST. Clustering of STs was performed with the Sequence Type Analysis and Recombinational Tests (START) program [27]. The matrix of pair-wise distances between the allelic profiles was converted to NEXUS files, and the split decomposition was analysed with the Splits Tree software program, vs. 4 [28]. Splits tree allowed researchers to visualise clustering within the population and to detect recombination between STs. The nucleotide sequences determined in this study for the different alleles of each locus have been deposited in the EMBL database under the accession numbers HE586270 to HE586309.

\section{Analysis by MALDI-TOF mass spectrometry}

Matrix-assisted linear desorption/ionisation-time-offlight mass spectrometry (MALDI-TOF MS) analyses for all strains were performed at Anagnostec, GmbH, Germany [29], as described Scotta et al. [30].

\section{Results}

Phenotypic characterisation and antibiotic susceptibility tests of the isolates

All colonies were pale yellow in colour, nonhemolytic, catalase positive and oxidase negative. The strains were identified by the RapID CB Plus ${ }^{\circledR}$ strips as C. striatum (51 strains with a confidence level between $85.54 \%$ 99.97\%), C. pseudodiphtheriticum (2 strains with a $100 \%$ of confidence level), or C. amycolatum (1 strain with a confidence level of 51.26\%) [Additional file 3: Table S3]. All isolates were susceptible to vancomycin and resistant to cefotaxime and ciprofloxacin, whereas susceptibilities to other antibiotics tested were heterogeneous (Additional file 4: Table S4). The type strain of C. amycolatum was susceptible to all the antibiotics tested. The $C$. striatum type strain was susceptible to all of the antibiotics except cefotaxime. The two isolates that were analysed from the CCUG were sensitive to antibiotics.

\section{ERIC-PCR}

Groupings based on the most similar fingerprint type of ERIC-PCR generated seven different profiles (represented by strains $2,11,15,19,31,60$ and 70) for $C$. striatum strains. The profile of the type strain of $C$. striatum was different from those of the clinical isolates; differences between the isolates were also observed (see Additional file 5: Figure S1).

\section{Multilocus sequence typing}

Seven genes were determined for most of the strains studied. The $16 \mathrm{~S}$ rRNA gene was excluded from the exhaustive analysis because of the high conservation between all of the strains studied; it was only used as a control to check the authenticity of the strains. Clinical isolates 16 and 17, characterised by phenotypical methods as $C$. pseudodiphtheriticum, were affiliated with the $C$. striatum species as determined by molecular methods. The $\operatorname{erm} X, a p h A$ and $\operatorname{sod} A$ genes were also excluded from the analysis because of the high conservation between all strains.

The ITS1, gyr $A$ and $r p o B$ genes were used to discriminate between strains, although the genes differed at few nucleotide changes within the sequences. The sequence analysis of ITS1 demonstrated the presence of more than one $r r n$ operon in most of the strains, which was not appreciable in the agarose gel as a double band but was detectable in the sequence electropherogram. The presence of more than one operon was checked by cloning of four PCR products (data not shown). Analysis of the gyr $A$ and $r p o B$ genes revealed that the variability 
Table 1 STs at the eight loci examined in the $C$. striatum and C. amycolatum strains studied

\begin{tabular}{|c|c|c|c|c|c|c|c|c|c|}
\hline Strain & 16Sr DNA & ITS1 & gyrA & $r p o B$ & hsp65 & $\operatorname{sod} A$ & ermX & $a p h A$ & $\mathrm{ST}^{*}$ \\
\hline 2 & 1 & 3 & 2 & 2 & 1 & 1 & 1 & 1 & 1 \\
\hline 7 & 1 & 3 & 2 & 2 & 1 & 1 & 1 & 1 & 1 \\
\hline 9 & 1 & 6 & 2 & 2 & 1 & - & 1 & 1 & 2 \\
\hline 11 & 1 & 1 & 3 & 2 & 1 & 1 & 1 & 1 & 3 \\
\hline 12 & 1 & 1 & 3 & 2 & 1 & - & 1 & 1 & 3 \\
\hline 14 & 1 & 6 & 2 & 2 & 1 & 1 & 1 & 1 & 2 \\
\hline 15 & 1 & 4 & 3 & 2 & 1 & - & 1 & 1 & 4 \\
\hline 16 & 1 & 4 & 3 & 2 & 1 & 1 & 1 & 1 & 4 \\
\hline 17 & 1 & 2 & 2 & 2 & 1 & 1 & 1 & 1 & 5 \\
\hline 18 & 1 & 4 & 3 & 2 & 1 & - & 1 & 1 & 4 \\
\hline 19 & 1 & 1 & 3 & 2 & 1 & - & 1 & 1 & 3 \\
\hline 21 & 1 & 6 & 2 & 2 & 1 & 1 & 1 & 1 & 2 \\
\hline 23 & 1 & 6 & 2 & 2 & 1 & 1 & 1 & 1 & 2 \\
\hline 24 & 1 & 2 & 2 & 2 & 1 & 1 & 1 & - & 5 \\
\hline 25 & 1 & 3 & 2 & 2 & 1 & 1 & 1 & 1 & 1 \\
\hline 26 & 1 & 6 & 2 & 2 & 1 & 1 & 1 & 1 & 2 \\
\hline 28 & 1 & 7 & 3 & 2 & 1 & 1 & 1 & 1 & 6 \\
\hline 29 & 1 & 5 & 2 & 2 & 1 & 1 & 1 & 1 & 7 \\
\hline 30 & 1 & 4 & 3 & 4 & 1 & 1 & 1 & 1 & 8 \\
\hline 31 & 1 & 6 & 2 & 2 & 1 & 1 & 1 & 1 & 2 \\
\hline 35 & 1 & 6 & 2 & 2 & 1 & - & 1 & 1 & 2 \\
\hline 36 & 1 & 6 & 2 & 2 & 1 & 1 & 1 & 1 & 2 \\
\hline 41 & 1 & 6 & 2 & 2 & 1 & 1 & 1 & 1 & 2 \\
\hline 42 & 1 & 6 & 2 & 2 & 1 & - & 1 & 1 & 2 \\
\hline 43 & 1 & 3 & 2 & 2 & 1 & - & 1 & - & 1 \\
\hline 44 & 1 & 4 & 3 & 2 & 1 & - & 1 & 1 & 4 \\
\hline 46 & 1 & 3 & 2 & 2 & 1 & 1 & 1 & 1 & 1 \\
\hline 47 & 1 & 4 & 3 & 2 & 1 & 1 & 1 & 1 & 4 \\
\hline 48 & 1 & 2 & 2 & 2 & 1 & 1 & 1 & - & 5 \\
\hline 50 & 1 & 4 & 3 & 2 & 1 & 1 & 1 & 1 & 4 \\
\hline 51 & 1 & 10 & 4 & 2 & 1 & - & 1 & - & 9 \\
\hline 53 & 1 & 2 & 2 & 2 & 1 & 1 & 1 & 1 & 5 \\
\hline 54 & 1 & 3 & 2 & 2 & 1 & 1 & 1 & - & 1 \\
\hline 55 & 1 & 6 & 2 & 2 & 1 & 1 & 1 & 1 & 2 \\
\hline 56 & 1 & 1 & 3 & 2 & 1 & - & 1 & 1 & 3 \\
\hline 57 & 1 & 4 & 3 & 2 & 1 & 1 & 1 & 1 & 4 \\
\hline 58 & 1 & 4 & 3 & 2 & 1 & 1 & 1 & 1 & 4 \\
\hline 59 & 1 & 4 & 3 & 2 & 1 & - & 1 & 1 & 4 \\
\hline 60 & 1 & 4 & 3 & 2 & 1 & 1 & 1 & 1 & 4 \\
\hline 61 & 1 & 12 & 3 & 3 & 1 & 1 & 1 & - & 10 \\
\hline 62 & 1 & 7 & 3 & 3 & 1 & - & 1 & 1 & 11 \\
\hline 63 & - & 7 & 3 & 3 & 1 & - & 1 & 1 & 11 \\
\hline 64 & 1 & 7 & 3 & 3 & 1 & 1 & 1 & - & 11 \\
\hline 65 & 1 & 7 & 3 & 3 & 1 & - & 1 & - & 11 \\
\hline 66 & 1 & 4 & 3 & 4 & 1 & 1 & 1 & 1 & 8 \\
\hline 67 & 1 & 7 & 3 & 3 & 1 & 1 & 1 & - & 11 \\
\hline 68 & 1 & 7 & 3 & 3 & 1 & - & 1 & - & 11 \\
\hline 69 & 1 & 9 & 5 & 4 & 2 & 1 & 1 & - & 12 \\
\hline 70 & 2 & 13 & 7 & 6 & 3 & 2 & 1 & 1 & 13 \\
\hline 71 & 1 & 11 & 4 & 2 & 1 & 1 & 1 & 1 & 14 \\
\hline 73 & 1 & 4 & 3 & 4 & 1 & 1 & 1 & - & 8 \\
\hline
\end{tabular}


Table 1 STs at the eight loci examined in the C. striatum and C. amycolatum strains studied (Continued)

\begin{tabular}{|c|c|c|c|c|c|c|c|c|c|}
\hline 74 & 1 & 8 & 3 & 4 & 1 & - & 1 & 2 & 15 \\
\hline C. striatum ATCC $6940^{\top}$ & 1 & 17 & 1 & 1 & 1 & - & 1 & - & 16 \\
\hline C. amycolatum CCUG $35685^{\top}$ & 5 & 14 & 3 & 7 & 4 & - & - & - & 17 \\
\hline CCUG 39137 & 3 & 15 & 3 & 6 & 3 & - & - & 2 & 18 \\
\hline CCUG 44705 & 4 & 16 & 6 & 5 & 1 & - & - & - & 19 \\
\hline
\end{tabular}

* ST number was obtained taking into account only three of the eight loci analyzed (ITS1 region, gyrA, and rpoB genes)

between different Corynebacterium species occurred throughout the gene, while the variability in the clinical C. striatum isolates was confined to certain areas near the beginning of the gene.

Distinct allele sequences were assigned arbitrary allele numbers for each locus (Table 1). Calculated allele and nucleotide diversities are shown in Table 2. The number of polymorphic sites and the haplotype and nucleotide diversity were not calculated for the ITS1 region because, in most cases, more than one operon was detected. 16S rDNA, erm X, aphA, sodA and hsp65 were not appropriate genes for studying the genetic diversity of the strains, although these genes could be used to differentiate between Corynebacterium species. gyrA and $r р о B$ were appropriate genes to study genetic diversity, with 116 and 39 polymorphic sites, respectively. In the ITS1 region, the most abundant alleles were 4 (23.2\%), 6 (19.6\%), 7 (12.5\%), 3 (10.7\%), and alleles 1 and 2 (7.1\%). Each one of the other alleles for ITS1, representing $19.6 \%$ of the population, is represented by a single strain. For the gyrA gene, two alleles (number 2 and 3) were predominant (90\%). For the rpoB gene, allele 2 is the most abundant and is found in 39 strains (69.6\%).
Considering these three genes, four STs were the most abundant: ST2, ST4, ST1 and ST11, occurring in 11, 10, 6 and 6 strains, respectively.

To determine the possible lateral gene transfers occurring in the population of Corynebacterium strains studied and taking into account the ITS1, gyrB and $r p o B$ gene allelic profiles, a splits tree was constructed for all analysed strains (Figure 1, panel A) and only with the $C$. striatum strains (Figure 1, panel B). Some strains have two or three identical genes. Type strains of C. striatum and $C$. amycolatum did not share any allele, and recombination was detected between all of the C. striatum isolates. Different clonal populations could be detected, as shown in Figure 1.

\section{Bacterial analysis by MALDI-TOF mass spectrometry}

In the MALDI-TOF MS cluster analysis, the Corynebacterium species could be clearly differentiated from one another with less than 50\% similarity. MALDI-TOF MS profiles for all of the strains studied have been included as Additional files 6: Figure S2. All the strains analysed clustered in four different groups (with similarities higher than 60\%): the cluster of C. striatum included

Table 2 Genetic diversity of the selected loci among the Corynebacterium strains analysed

\begin{tabular}{|c|c|c|c|c|c|c|c|}
\hline $\begin{array}{l}\text { No. of } \\
\text { strains }\end{array}$ & Locus & $\begin{array}{l}\text { Fragment } \\
\text { length }(b p)^{£}\end{array}$ & $\begin{array}{l}\text { No. of } \\
\text { alleles }\end{array}$ & $\begin{array}{l}\text { Haplotype (gene) } \\
\text { diversity } \pm S D\end{array}$ & $\begin{array}{c}\text { No. of } \\
\text { polymorphic } \\
\text { sites }\end{array}$ & $\begin{array}{l}\text { Avg number of nucleotide } \\
\text { differences }\end{array}$ & $\begin{array}{c}\text { Nucleotide } \\
\text { diversity } \pm \text { SD }\end{array}$ \\
\hline $56(48)$ & $\begin{array}{l}16 S \\
\text { rDNA }\end{array}$ & 872 & $5(1)$ & $0.722 \pm 0.159$ & $71(0)$ & 31.972 & $0.037 \pm 0.007$ \\
\hline $56(49)$ & $\mid \mathrm{TS} 1^{¥}$ & $360^{¥}$ & $17(10)$ & - & - & - & - \\
\hline $56(49)$ & gyrA & 200 & $7(3)$ & $0.604 \pm 0.040(0.527 \pm$ & $39(3)$ & $\begin{array}{c}2.452 \\
(1.073)\end{array}$ & $\begin{aligned} 0.012 & \pm 0.006(0.005 \\
& \pm 0.000)\end{aligned}$ \\
\hline $56(49)$ & $r p o B$ & 380 & $7(3)$ & $\begin{array}{c}0.498 \pm 0.076 \\
(0.379 \pm 0.079)\end{array}$ & $116(4)$ & $11.551(0.912)$ & $\begin{array}{l}0.0314 \pm 0.012 \\
(0.002 \pm 0.000)\end{array}$ \\
\hline $56(49)$ & hsp65 & 287 & $4(1)$ & $0.138 \pm 0.062(0 \pm 0)$ & $62(0)$ & $\begin{array}{l}6.199 \\
(0)\end{array}$ & $\begin{array}{l}0.022 \pm 0.011 \\
\quad(0 \pm 0)\end{array}$ \\
\hline $35(32)$ & $\operatorname{sod} A$ & 295 & $2(1)$ & $0.057 \pm 0.053(0 \pm 0)$ & $64(0)$ & $\begin{array}{l}3.657 \\
(0)\end{array}$ & $\begin{array}{l}0.012 \pm 0.011 \\
\quad(0 \pm 0)\end{array}$ \\
\hline $53(49)$ & ermX & 367 & $1(1)$ & $\begin{array}{c}0 \pm 0 \\
(0 \pm 0)\end{array}$ & $0(0)$ & $\begin{array}{c}0 \\
(0)\end{array}$ & $\begin{array}{c}0 \pm 0 \\
(0 \pm 0)\end{array}$ \\
\hline $41(38)$ & $a p h A$ & 333 & $2(2)$ & $0.095 \pm 0.061(0.053 \pm$ & $1(1)$ & $\begin{array}{c}0.095 \\
(0.053)\end{array}$ & $0.0003 \pm 0.0002(0 \pm$ \\
\hline
\end{tabular}

The values corresponding only to clinical strains of $C$. striatum are given within brackets

${ }^{ \pm}$The number indicated the length of the sequenced fragment used for the polymorphic analysis

¥ The number of polymorphic sites, and the haplotype and nucleotide diversity was not calculated for the ITS1 region because in most cases more than one operon was detected. The number of alleles was established directly from the alignment 


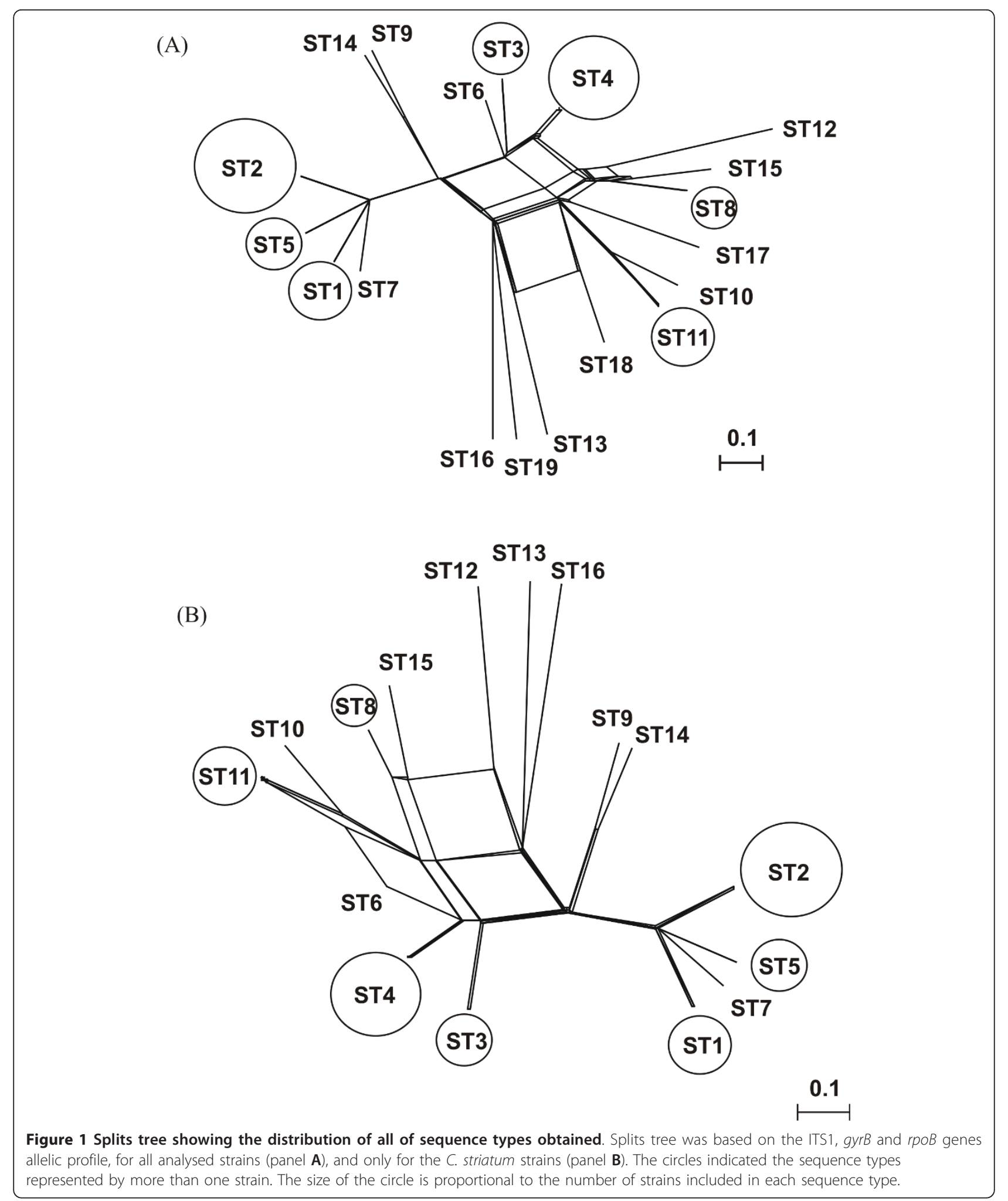

most of the clinical isolates and the type strain of $C$. striatum, and the cluster of $C$. amycolatum included the type strain, isolate CCUG 39137, the clinical isolate 70 (similarity higher than 60\%), and two branches, including a single strain, the clinical isolate 69 and the environmental Corynebacterium CCUG 44705. The duplicate 
spectra for each strain analysed clustered at $60 \%$ similarity or higher. At a $70 \%$ similarity level, three subclusters could be distinguished in the C. striatum branch. Isolates 16 and 17 were identified as C. pseudodiphtheriticum by the RapID CB Plus ${ }^{\circledR}$ strips, the method routinely used for identification in clinical laboratories, but they clustered within the C. striatum group in the MALDI-TOF analysis, in accordance with the sequencing analysis. These data further support that MALDITOF MS is an appropriate tool to differentiate and discriminate species, even at the level of expression of the most abundant cellular proteins.

\section{Discussion}

Strains of C. striatum isolated from cultures of sputum of respiratory samples from patients with COPD were studied in order to find possible differences between them and the type strain. In general, this group of organisms is well identified by current phenotypic methods, but in some cases, there is a lack of specificity that may result in ambiguous or even erroneous identification. Correct identification of bacteria remains critical for the detection of outbreaks in specific populations of patients and for the surveillance of bacteria within patients.

Phenotypic characterisation and antibiotic-resistance profiles did not clearly distinguish between $C$. striatum strains. All strains were identifiable by the RapID CB Plus ${ }^{\circledR}$ strips system, with three different identifications being generated. All identifications had confidence levels higher than $85.54 \%$. Antibiotic-resistance profiles for $C$. striatum clinical isolates were heterogeneous in the different antibiotics tested, whereas the type strains of $C$. amycolatum and C. striatum, as well as the external controls analysed, were mainly susceptible to the antibiotics tested.

Differences within clinical C. striatum isolates were identified with PCR amplification and the sequencing of several genes. Of all the genes analysed, the ITS1 region and the gyrA and rpoB genes, due to their variability, were the most adequate to discriminate between strains, although ITS1 did not allow for calculations of genetic diversity because of the presence of more than one $\mathrm{rrn}$ operon. These genes were more polymorphic than the other genes tested. The analyses provided an appropriate identification of C. striatum strains and allowed for distinguishing between clinical isolates. Molecular analysis allows species discrimination, unlike phenotypic analysis, which sometimes misidentifies strains.

The 56 strains represent distinct allele combinations (19 STs, considering only three genes: ITS1, gyrA and rрoB); 11, 10, 6, and 6 strains showed identical allelic profiles (sequetypes 2, 4, 1 and 11, corresponding to the allelic profiles 6-2-2, 4-3-2, 3-2-2 and 7-3-3). All of the
C. striatum clinical isolates were different from the type strain, and recombination events could be detected between them, supporting the hypothesis that these groups represent genetically similar strains.

The identification of strains based on molecular methods was also confirmed by MALDI-TOF mass spectrometry. The bacteria identified were exactly the same with both methods. As suggested by Seng et al. [15], MALDI-TOF may represent a rapid, inexpensive, alternative assay for identification of bacteria at the species level. These results were also in agreement with data obtained by Bittar et al. [8]. Our results suggest that MALDI-TOF mass spectrometry could also be a beneficial tool for discrimination of bacterial strains discrimination below the species level, but it is not as efficient as the molecular analysis for identifying strains. Further studies to evaluate the typing power should be performed.

\section{Conclusions}

In summary, our results demonstrate that the isolates obtained were best identified with gene-based molecular methods and that they were different from the type strain of C. striatum. Additionally, the ITS1 region and the gyrA and rpoB genes are the most useful tools to discriminate between strains because of their variability, unlike the phenotype and antibiotype, which are not suitable for this purpose. Our results suggest that MALDITOF mass spectrometry is a good tool for C. striatum identification and for discriminating bacterial strains below the species level.

\section{Additional material}

\footnotetext{
Additional file 1: Table S1. List of isolates analysed, their origin and sample type. External strains for comparison purposes have been included in the study: the type strains C. amycolatum CCUG $35685^{\top}$ and C. striatum ATCC $6940^{\top}$, as well as two strains of C. striatum with different origins, CCUG 39137 (from a human wound) and CCUG 44705 (tobacco industry).

Additional file 2: Table S2. Primers used for performing the molecular analysis of the 56 Corynebacterium strains.

Additional file 3: Table S3. Phenotypic results of RapID CB Plus ${ }^{\mathbb{R}_{\circledast}}$ tests for the different strains analysed.

Additional file 4: Table S4. Antibiotic susceptibility pattern of each strain analysed. The antibiotics tested for all strains were penicillin (PEN), imipenem (IMI), erythromycin (ERI), rifampicin (RIF), tetracycline (TET), vancomycin (VAN), ciprofloxacin (CIP), gentamicin (GEN), cefotaxime (CEF), and trimethoprim-sulfamethoxazole (TRI). R, resistant; I, intermediate; S, susceptible.

Additional file 5: Figure S1. ERIC-PCR patterns of the different $C$. striatum clinical isolates analysed. The number on the top of the lane corresponds to the number of clinical isolate studied; $\mathrm{Cs}^{\top}, \mathrm{C}$. striatum ATCC $6940^{\top}$. M1, Marker $\lambda_{E / H} ;$ M2, marker $100 \mathrm{bp}$.

Additional file 6: Figure S2. SARAMIS cluster analysis of all Corynebacterium strains isolated.
} 


\section{Acknowledgements}

This work was supported by the General Board for Research, Technological Development and Innovation of the Department of Finance and Innovation of the Autonomous Community of the Balearic Islands (Direcció General de Recerca, Desenvolupament Tecnològic i Innovació, de la Conselleria d'Hisenda i Innovació, de la Comunitat Autònoma de les Illes Balears). M. Gomila is the recipient of a postdoctoral contract from the Juan de la Cierva Programme of the Spanish Ministerio de Ciencia e Innovación.

\section{Author details}

'Unidad de Investigación-Microbiología, Fundación Hospital Son Llàtzer, Ctra. Manacor, km. 4, 07198 Palma de Mallorca, Illes Balears, Spain. ${ }^{2}$ Respiratory Unit, Hospital Joan March, Ctra. Sóller, km. 12, 07110 Bunyola, Illes Balears, Spain. ${ }^{3}$ Microbiology Service, Fundación Hospital Son Llàtzer, Ctra. Manacor, km. 4, 07198 Palma de Mallorca, Illes Balears, Spain. ${ }^{4}$ Program of Epidemiology and Clinical Research, Fundació Caubet-CIMERA Illes Balears, International Centre for Advanced Respiratory Medicine, Ctra. Sóller, km. 12, 07110 Bunyola, Illes Balears, Spain. ${ }^{5}$ Microbiologia, Departament de Biologia, Universitat de les Illes Balears, and Institut Mediterrani d'Estudis Avançats (CSIC-UIB), Ctra. Valldemossa, km. 7.5, 07122 Palma de Mallorca, Illes Balears, Spain.

\section{Authors' contributions}

MGo carried out the molecular genetic studies, participated in the sequence analysis and drafted the manuscript. FR coordinated samples collection and decided patient treatments. MCG and MGa carried out the isolation and phenotypic and the antibiogram analysis. FR, JBS and JL conceived the study. All co-authors participated in the design of the study and coordination and helped to the draft manuscript. All authors read and approved the final manuscript.

Received: 30 September 2011 Accepted: 4 April 2012 Published: 4 April 2012

\section{References}

1. Bolt F, Cassiday P, Tondella ML, De Zoysa A, Efstratiou A, Sing A, Zasada A, Bernard K, Guiso N, Badell E, Rosso M-L, Baldwin A, Dowson C: Multilocus sequence typing identifies evidence for recombination and two distinct lineages of Corynebacterium diphtheriae. J Clin Microbiol 2010, 48:4177-4185.

2. De Briel $D$, Langs JC, Rougeron $G$, Chabot $P$, Le Faou A: Multiresistant corynebacteria in bacteriuria: a comparative study of the role of Corynebacterium group D-2 and Corynebacterium jeikeium. J Hosp Infect 1991, 17:35-43.

3. Riegel P, Ruimy R, Christen R, Monteil H: Species identities and antimicrobial susceptibilities of corynebacteria isolated from various clinical resources. Eur J Clin Microbiol Infect Dis 1996, 15:657-662.

4. Riegel P, Ruimy R, de Briel D, Prevost G, Jehl F, Christen R, Monteil H: Genomic diversity and phylogenetic relationships among lipid-requiring diphtheroids from humans and characterization of Corynebacterium macginleyi sp. nov. Int J Syst Bacteriol 1995, 45:128-133.

5. Funke G, Lawson PA, Bernard KA, Collins MD: Most Corynebacterium xerosis strains identified in the routine clinical laboratory correspond to Corynebacterium amycolatum. J Clin Microbiol 1996, 34:1124-1128.

6. Martaresche C, Fournier PE, Jacomo V, Gainnier M, Boussuge A, Drancourt M: A case of Corynebacterium pseudodiphtheriticum nosocomial pneumonia. Emerg Infect Dis 1999, 5:722-723.

7. Miller RA, Rompalo A, Coyle MB: Corynebacterium pseudodiphtheriticum pneumonia in an immunologically intact host. Diagn Microbiol Infect Dis 1986, 4:165-171.

8. Bittar F, Cassagne C, Bosdure E, Stremler N, Dubus JC, Sarles J, ReynaudGaubert M, Raoult D, Rolain JM: Outbreak of Corynebacterium pseudodiphtheriticum infection in cystic fibrosis patients, France. Emerg Infect Dis 2010, 16:1231-1236.

9. Leonard RB, Nowowiejski DJ, Warren JJ, Finn DJ, Coyle MB: Molecular evidence of person-to-person transmission of a pigmented strain of Corynebacterium striatum in Intensive Care Units. J Clin Microbiol 1994, 32:164-169.

10. Brandenburg AH, van Belkum A, Van Pelt C, Bruining HA, Mouton JW, Verbrugh HA: Patient-to-patient spread of a single strain of
Corynebacterium striatum causing infections in a surgical Intensive Care Unit. J Clin Microbiol 1996, 34:2089-2094.

11. Otsuka Y, Ohkusu K, Kawamura Y, Baba S, Ezaki T, Kimura S: Emergence of multidrug-resistant Corynebacterium striatum as a nosocomial pathogen in long-term hospitalized patients with underlying diseases. Diagn Microbiol Infect Dis 2006, 54:109-114.

12. Renom F, Garau M, Rubí M, Ramis F, Galmés A, Soriano JB: Nosocomial outbreak of Corynebacterium striatum infection in patients with chronic obstructive pulmonary disease. J Clin Microbiol 2007, 45:2064-2067.

13. Funke G, von Graevenitz A, Clarridge JE III, Bernard KA: Clinical microbiology of coryneform bacteria. Clin Microbiol Rev 1997, 10:125-159.

14. Maiden MC, Bygraves JA, Feil E, Morelli G, Russell JE, Urwin R, Zhang Q, Zhou J, Zurth K, Caugant DA, Feavers IM, Achtman M, Spratt BG: Multilocus sequence typing: a portable approach to the identification of clones within populations of pathogenic microorganisms. Proc Natl Acad Sci USA 1998, 95:3140-3145.

15. Seng P, Drancourt M, Gouriet F, La Scola B, Fournier PE, Rolain JM, Raoult D: Ongoing revolution in bacteriology: routine identification of bacteria by matrix-assisted laser desorption ionization time-of-flight mass spectrometry. Clin Infect Dis 2009, 49:543-551.

16. Welker M, Moore ER: Applications of whole-cell matrix-assisted laserdesorption/ionization time-of-flight mass spectrometry in systematic microbiology. Syst Appl Microbiol 2011, 34:2-11.

17. Murray PR, Washington JA: Microscopic and bacteriologic analysis of expectorated sputum. Mayo Clin Proc 1975, 50:339-344.

18. Clinical and Laboratory Standards Institute: Methods for antimicrobial dilution and disk susceptibility testing of infrequently isolated or fastidious bacteria; Approved Guideline, M45-A Wayne PA, USA: CLSI; 2006.

19. Gomila M, Ramírez A, Lalucat J: Diversity of environmental Mycobacterium isolates from hemodialysis water as shown by a multigene sequencing approach. Appl Environ Microbiol 2007, 73:3787-3797.

20. Versalovic J, Koeuth T, Lupski JR: Distribution of repetitive DNA sequences in eubacteria and application to fingerprinting of bacterial genomes. Nucleic Acids Res 1991, 19:6823-6831.

21. Lane DJ: $16 S / 23 S$ rDNA sequencing. In Nucleic acid techniques in bacterial systematics. Edited by: Stackebrand E, Goodfellow M. Chichester, United Kingdom: Wiley; 1991:115-175.

22. Guasp C, Moore ER, Lalucat J, Bennasar A: Utility of internally transcribed 16S-23S rDNA spacer regions for the definition of Pseudomonas stutzeri genomovars and other Pseudomonas species. Int I Syst Evol Microbiol 2000, 50:1629-1639.

23. Sierra JM, Martinez-Martinez L, Vázquez F, Giralt E, Vila J: Relationship between mutations in the gyrA gene and quinolone resistance in clinical isolates of Corynebacterium striatum and Corynebacterium amycolatum. Antimicrob Agents Chemother 2005, 49:1714-1719.

24. Khamis A, Raoult D, La Scola B: rpoB gene sequencing for identification of Corynebacteriu species. J Clin Microbiol 2004, 42:3925-3931.

25. Campanile F, Carretto E, Barbarini D, Grigis A, Falcone M, Goglio A, Venditti M, Stefani S: Clonal multidrug-resistant Corynebacterium striatum strains, Italy. Emerg Infect Dis 2009, 15:75-78.

26. Librado P, Rozas J, DnaSP v5: A software for comprehensive analysis of DNA polymorphism data. Bioinformatics 2009, 25:1451-1452.

27. Jolley KA, Feil EJ, Chan MS, Maiden MC: Sequence type analysis and recombinational tests (START). Bioinformatics 2001, 17:1230-1231.

28. Huson DH, Bryant D: Application of phylogenetic networks in evolutionary studies. Mol Biol Evol 2006, 23:254-267.

29. Kallow W, Erhard M, Shah HN, Raptakis E, Welker M: MALDI-TOF MS for microbial identification: years of experimental development to an established protocol. In Mass Spectrometry for Microbial Proteomics. Edited by: Shah HN, Gharbia SE, Encheva V. London: John Wiley 2010:

30. Scotta C, Bennasar A, Moore ERB, Lalucat J, Gomila M: Taxonomic characterisation of ceftazidime-resistant Brevundimonas isolates and description of Brevundimonas faecalis sp. Syst Appl Microbiol 2011, 34:408-413.

doi:10.1186/1471-2180-12-52

Cite this article as: Gomila et al: Identification and diversity of multiresistant Corynebacterium striatum clinical isolates by MALDI-TOF mass spectrometry and by a multigene sequencing approach. $B M C$ Microbiology 2012 12:52. 